\title{
Genesis of high frequency heart sounds
}

Sir, The recent paper by Traill et al. (Br Heart $\mathcal{f}$ 1982; 48: 78-80) provides interesting support for the valvular genesis of high frequency heart sounds.

As was shown by Mills et al., ${ }^{1}$ we were able to record a diastolic heart sound simultaneously with echocardiographe mitral valve closure in a "normal" patient with congenital heart block. The intensity of such sounds, however, never reached the level of the true normal mitral component of the first sound. As Traill suggests, that intensity can occur only if there is an abrupt rise in ventricular diastolic pressure inducing sudden termination of forward flow across the mitral valve, but that means also the establishment of an increasing pressure gradient across the mitral valve enhanced by the atrial relaxation. In our own study, ${ }^{2}$ we have assessed the timing of the mitral component of the first sound with the simultaneous recording of echocardiographic mitral valve closure and the apex cardiogram and its first derivative, the latter giving a good estimate of the variation of left ventricular wall tension and thus of left ventricular pressure. ${ }^{3} \mathrm{We}$ found a very close correlation between the mitral component of the first heart sound and mitral valve closure, and, as Luisada et al. ${ }^{45}$ had previously shown there was a correlation with the left ventricular pressure derivative, and a lesser but highly significant correlation between mitral valve closure and the first peak of the apex cardiogram derivative. Therefore, like Palfrey, ${ }^{6}$ we suggest a valvulomuscular theory in the genesis of high frequency heart sounds. These sounds occur after valvular coaptation at the time of maximum tension: their loudness is a direct function of the rate of the developed pressure gradient across the valve just before coaptation through active (contraction) and passive (relaxation) myocardial mechanisms. This theory also enables us to explain the existence of a loud diastolic mitral component of the first sound in the particular case of Traill, the simultaneous recording of the apex cardiogram showing clearly the very sharp combined rapid filling wave well related to the fourth sound and ended by an unusual notch clearly time related to mitral valve closure and the mitral component of the first heart sound. That notch is evidence of a pressure transient caused by abrupt cessation of inflow.

S Drui, CM Brandt, JL Fincker, Service de Cardiologie, Clinique Médicale B, CHU 67091 Strasbourg Cedex

France.

This letter was shown to Dr Traill and his colleagues who reply as follows:

Sir,

We are grateful for the interest of Dr Drui and coworkers. Mills, Craige, and others interested in heart sounds and valve movements have provided many illustrations of the way in which the velocity of valve closing influences the loudness of the corresponding sound. It is intuitively reasonable that the velocity of closure should depend upon the pressures causing it and so in this sense we could all be considered members of a "valvulomuscular" school.

We would still take issue with any suggestion that the correlation between intensity of sound and rate of left ventricular pressure rise was explained in terms of a primarily myocardial origin of the vibrations.

Thomas A Traill,

The Johns Hopkins Hospital,

Baltimore, Maryland 21205,

USA.

\section{References}

1 Mills PG, Chamusco RF, Moos S, Craige E. Echophonocardiographic studies of the contribution of the atrioventricular valves to the first heart sound. Circulation 1976; 54: 944-51.

2 Drui S, Brandt CM, Fincker JL. Analyse chronologique des variations de vélocité de la pente ascendante du cardiogramme apexien. Arch Mal Coeur 1982; 75: 1277-86.

3 Aubert AE, Denef B, Van de Werf F, Kesteloot H. 
Echo-mechanocardiographic assessment of cardiac dynamics. In: Lancée CT, ed. Echocardiology. (Developments in Cardiovascular medicine, 1.) The Hague: Martinus Nijhoff, 1979: 5-13.

4 Shah PM, Mori M, MacCanon DM, Luisada AA. Hemodynamic correlates of the various components of the first heart sound. Circ Res 1963; 12: 386-92.

5 Luisada AA, MacCanon DM, Kumar S, Feigen LP. Changing views on the mechanism of the first and second? heart sounds. Am Heart f 1974; 88: 503-14.

6 Palfrey FW. The cause of the first heart sound. N Engl $f$ 음 Med 1929; 200: 917-8.

\section{Notice}

\section{British Cardiac Society}

The Annual General Meeting for 1983 will take place in Bristol on 13 and 14 April, and the closing date for abstracts was 4 January 1983.

The Autumn Meeting will be held at Wembley on 21 and 22 November 1983, and the closing date for abstracts will be 28 July 1983. 